\title{
Las configuraciones locales de odio. Discursos antimigratorios y prácticas xenofóbicas en Foz de Iguazú, Brasil
}

\author{
The local configurations of hate. Anti-migratory \\ discourses and xenophobic practices in Foz do \\ Iguaçu, Brazil
}

Recibido el 30 de octubre de 2019. Aceptado el 13 de marzo de 2020. Publicado el 19 de marzo de 2020.

*Autora para correspondencia: Menara Lube Guizardi. Correo electrónico: menaraguizardi@yahoo.com.br

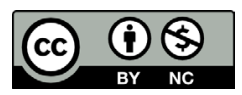

Esta obra está protegida bajo una Licencia Creative Commons Atribución-NoComercial 4.0 Internacional.
Menara Lube Guizardia* (D) https://orcid.org/0000-0003-2670-9360 Pablo Mardones ${ }^{b}$ (D) https://orcid.org/0000-0002-4490-1391

${ }^{a}$ Consejo Nacional de Investigaciones Científicas y Técnicas (CONICET) en el Instituto de Altos Estudios Sociales de la Universidad Nacional de San Martín, Buenos Aires, Argentina (IDAES.UNSAM); Universidad de Tarapacá, Arica, Chile, correo electrónico: menaraguizardi@yahoo.com.br b Instituto de Estudios Internacionales de la Universidad Arturo Prat, Iquique, Chile, correo electrónico: mardones.pablo@gmail.com

\section{Resumen}

El objetivo del artículo es describir etnográficamente los impactos sociales de los discursos de odio antimigratorio en la ciudad brasileña de Foz de Iguazú (en la triple frontera del Paraná). Analizamos el actual contexto político brasileño indagando el impacto presente de los imaginarios del militarismo distendido en estas fronteras desde 1970. Utilizamos una metodología etnográfica, con la realización de 60 entrevistas cualitativas y un grupo focal con 11 participantes (estudiantes migrantes internacionales, profesores y personal técnico de la Universidad de la Integración Latinoamericana). Los resultados arrojan que la xenofobia fue convertida en discurso oficial en Brasil, articulándose a enunciados que preconizan la intolerancia hacia las minorías y sectores vulnerables. Esto incide de forma particular en Foz, dadas las configuraciones fronterizas y militares de la ciudad. Asimismo, el estudio permite concluir que tanto los discursos como prácticas xenofóbicas están articulados por imaginarios racistas que impactan más fuertemente a las mujeres migrantes.

Palabras clave: discursos de odio, migración, triple frontera del Paraná, Foz de Iguazú.

\section{Abstract}

The objective of the article is to ethnographically describe the social impacts of anti-migratory hate speeches in the Brazilian city of Foz do Iguaçu (in the

CÓMO CITAR: Guizardi, M. L. \& Mardones, P. (2020). Las configuraciones locales de odio. Discursos antimigratorios y prácticas xenofóbicas en Foz de Iguazú, Brasil. [The local configurations of hate. Anti-migratory discourses and xenophobic practices in Foz do Iguaçu, brazil]. Estudios Fronterizos, 21, e045. https://doi.org/10.21670/ref.2003045 
triple border of Paraná). We analyze the current Brazilian political context by investigating the present impact of the imaginations of militarism, disseminated on these borders since 1970. We use an ethnographic methodology, with 60 qualitative interviews and a focus group with 11 participants (international migrant students, teachers and technical staff from the University of Latin American Integration). The results show that xenophobia was converted into official discourse in Brazil, articulating statements that advocate intolerance towards minorities and vulnerable sectors. This particularly affects Foz, given the border and military configurations of the city. Likewise, the study allows us to conclude that both speeches and xenophobic practices are articulated by racist imaginary that most strongly impact migrant women.

Keywords: hate speech, migration, Paraná's tri-border-area, Foz do Iguaçu.

\section{Introducción}

Este artículo aborda las consecuencias sociales de los discursos de odio en contra de las poblaciones migrantes que caracterizan el giro reaccionario en el Cono Sur americano. Estos discursos reproducen lógicas simbólicas que se hicieron hegemónicas en el norte global (particularmente desde 2008), donde sirvieron como elementos movilizadores de la opinión pública en momentos decisivos (la votación del Brexit, en 2015, o la elección de Trump, en 2016) (Guizardi, 2019, p. 591). En Sudamérica, estas elaboraciones son propulsadas por medios de comunicación hegemónicos (Matossian et al., 2019, p. 31) que rescatan las configuraciones del racismo, androcentrismo y xenofobia que respaldaron los proyectos nacionales y los modelos de fronterización regionales (Canelo et al., 2018, p. 150-153). Articulan, así, imaginarios y mitos de larga duración con grande poder movilizador (Aquino, 2019, p. 180).

Nuestro objetivo es indagar cómo estos discursos impactan o movilizan ciertos contextos concretos, configurando las relaciones cotidianas de quienes reciben la etiqueta de "migrantes". El contexto elegido es la ciudad brasileña de Foz de Iguazú, localizada en la triple frontera del Paraná (donde colindan Argentina, Brasil y Paraguay), territorio caracterizado por una intensa circularidad transnacional (Agulló, 2017, p. 59; Cardin, 2012, p. 208; Renoldi, 2014, p. 2). No obstante, el estudio de caso que desarrollamos en las páginas que siguen tiene un carácter centralmente descriptivo-etnográfico: buscamos entregar informaciones empíricas cualitativas que permiten dar cuenta de las configuraciones locales del racismo y de la xenofobia antimigratoria en su enganche con los discursos de odio.

Para dar cuenta de estos propósitos, describiremos, en el segundo apartado, la metodología de nuestro estudio de caso, detallando las formas de recolección y análisis de la información cualitativa. En el tercer apartado discutiremos los usos discursivos empleados por el actual presidente de Brasil, Jair Bolsonaro, en contra de los migrantes. El cuarto apartado contextualiza las configuraciones urbanas e identitarias de Foz de Iguazú, explicitando su papel en la estructuración de las visiones de desarrollo y militarismo en Brasil en la última dictadura militar (19641986). Amparados en los relatos de nuestros entrevistados, abordaremos la creación 
de la Universidad Federal de Integración Latinoamericana (Unila) y su vinculación con los gobiernos del Partido de los Trabajadores (PT) en Brasil. Mostraremos la creciente impopularidad que estos gobiernos tuvieron en Foz desde 2013. El quinto apartado retoma los debates sostenidos en el grupo focal con estudiantes migrantes y trabajadores de la Unila, los "unileros", como son denominados (Alarcón, 2019). A través de sus relatos, abordaremos la legitimación de prácticas de odio en territorios donde las fricciones identitarias constituyen elementos cotidianos. Finalizaremos con algunas conclusiones sobre nuestro estudio de caso.

\section{Metodología}

Desde 2017 la primera autora de este artículo viene viajando a Foz para realizar observaciones etnográficas sobre la experiencia de las mujeres transfronterizas. El segundo autor se sumó a esta agenda investigativa en 2019, en el marco de un proyecto etnográfico comparativo entre fronteras sudamericanas. Dicho proyecto es dirigido por la primera autora y cuenta con la participación de un equipo de 12 investigadores/ as de diversos campos disciplinarios.

Los autores de este documento, junto a cuatro miembros del equipo, realizaron trabajo de campo en Foz entre julio y agosto de $2019,{ }^{1}$ registrando en diarios de campo, fotografías y filmaciones las experiencias de las poblaciones migrantes y transfronterizas. Además, realizaron un total de 60 entrevistas cualitativas: cuatro a misioneros católicos que trabajan en la atención a población migrante, tres a autoridades consulares, dos a mujeres argentinas, 14 a mujeres brasileñas, 31 a mujeres paraguayas, una a mujeres de otras nacionalidades, cinco a hombres brasileños y paraguayos. ${ }^{2}$ La Tabla 1 sintetiza los datos de los entrevistados citados.

Para complementar este material, realizamos un grupo focal con la presencia de 11 participantes, entre ellos, estudiantes migrantes internacionales y funcionarios de la Universidad de la Integración Latinoamericana (Unila). ${ }^{3}$ La actividad fue realizada el 20 de julio de 2019 en el campus de la Unila, de las 15:00 hs a las 18:00 hs. La Tabla 2 sintetiza la información de los participantes.

\footnotetext{
${ }^{1}$ Agradecemos a Carolina Stefoni, Herminia Gonzálvez, Eleonora López y Esteban Nazal, con quienes compartimos este trabajo etnográfico.

${ }^{2}$ En atención al reglamento ético de las agencias que financiaron el estudio, se usan las iniciales de los entrevistados para resguardar sus identidades. Se atendió, además, a sus solicitudes sobre cuáles informaciones divulgar y cuáles no.

${ }^{3}$ Agradecemos a Rodrigo de Medeiros da Silva (vicerrector de Relaciones Internacionales e Institucionales de la Unila) y de Silvia Lilian Ferro (del Instituto Latinoamericano de Economía, Sociedad y Política, Unila).
} 
Tabla 1. Descripción sintética de entrevistados citados

\begin{tabular}{|c|c|c|c|c|c|c|c|c|}
\hline Núm. & Iniciales & Nacionalidad & Sexo & Edad & Ocupación & $\begin{array}{c}\text { Localidad } \\
\text { de } \\
\text { residencia }\end{array}$ & Fecha & Registro \\
\hline 1 & I. & Brasileño & Masc. & 56 años & $\begin{array}{l}\text { Taxista (Extra- } \\
\text { bajador de la } \\
\text { construcción de } \\
\text { Itaipú) }\end{array}$ & Foz & 17.07.2019 & $\begin{array}{c}\text { Diario de } \\
\text { campo }\end{array}$ \\
\hline 2 & S. & Brasileño & Masc. & 50 años & $\begin{array}{l}\text { Taxista (Extra- } \\
\text { bajador de la } \\
\text { construcción de } \\
\text { Itaipú) }\end{array}$ & Foz & 31.08 .2019 & $\begin{array}{c}\text { Diario de } \\
\text { campo }\end{array}$ \\
\hline 3 & P. & Brasileño & Masc. & $\begin{array}{l}\text { No } \\
\text { declaró }\end{array}$ & $\begin{array}{l}\text { Taxista (Extra- } \\
\text { bajador de la } \\
\text { construcción de } \\
\text { Itaipú) }\end{array}$ & Foz & 19.08.2019 & $\begin{array}{l}\text { Diario de } \\
\text { campo }\end{array}$ \\
\hline 4 & TVTW & Brasileña & Fem. & 35 años & $\begin{array}{l}\text { Abogada y } \\
\text { empresaria }\end{array}$ & $\begin{array}{l}\text { Hernandarías } \\
\text { (Paraguay) }\end{array}$ & 01.08 .2019 & $\begin{array}{c}\text { Grabación } \\
\text { video }\end{array}$ \\
\hline 5 & SLF & Argentina & Fem. & 52 años & Cientista política & Foz & 01.08.2019 & $\begin{array}{c}\text { Grabación } \\
\text { video }\end{array}$ \\
\hline 6 & J. & Brasileño & Masc. & 65 años & Militar jubilado & Foz & 13.10 .2018 & $\begin{array}{c}\text { Diario de } \\
\text { campo }\end{array}$ \\
\hline
\end{tabular}

Fuente: elaboración propia.

Tabla 2. Participantes del grupo focal realizado en la Universidad de la Integración Latinoamericana (Unila). Foz de Iguazú (Brasil), 20/07/2019

\begin{tabular}{|c|c|c|c|c|c|}
\hline Núm. & Iniciales & Nacionalidad & Sexo & $\begin{array}{l}\text { Ocupación/ } \\
\text { carrera que cursa }\end{array}$ & $\begin{array}{l}\text { Ciudad de } \\
\text { residencia }\end{array}$ \\
\hline 1 & $\mathrm{AHC}$ & Venezolano/libanes & Masc. & $\begin{array}{l}\text { Estudiante de la licenciatura de } \\
\text { ciencia política y sociología }\end{array}$ & Foz \\
\hline 2 & RMVG & Paraguayo & Masc. & $\begin{array}{l}\text { Estudiante de la licenciatura de } \\
\text { ciencia política y sociología }\end{array}$ & Foz \\
\hline 3 & EMTP & Brasileño & Masc. & Administrativo de la Unila & Foz \\
\hline 4 & $\mathrm{CD}$ & Haitiana & Fem. & $\begin{array}{l}\text { Estudiante de administración } \\
\text { pública }\end{array}$ & Foz \\
\hline 5 & MLPH & Peruana & Fem. & $\begin{array}{l}\text { Estudiante de la licenciatura de } \\
\text { ciencia política y sociología }\end{array}$ & Foz \\
\hline 6 & $\mathrm{NCA}$ & Haitiana & Fem. & $\begin{array}{l}\text { Estudiante de ciencias políticas y } \\
\text { políticas públicas }\end{array}$ & Foz \\
\hline 7 & MBA & Colombiano & Masc. & Técnico en sonido & Foz \\
\hline 8 & FJVD & Colombiano & Masc. & $\begin{array}{l}\text { Estudiante de la licenciatura de } \\
\text { matemáticas }\end{array}$ & Foz \\
\hline 9 & JAMP & Colombiano & Masc. & $\begin{array}{l}\text { Estudiante de la licenciatura de } \\
\text { economía }\end{array}$ & Foz \\
\hline 10 & LKMA & Brasileña & Fem. & Profesora universitaria de epañol & Foz \\
\hline 11 & DMMF & Brasileño & Masc. & Estudiante de música & Foz \\
\hline
\end{tabular}

Fuente: elaboración propia. 
Las conversaciones fueron filmadas. La universidad constituye una institución bilingüe castellano/portugués donde cada persona elige el idioma de su preferencia: seguimos esta máxima para las entrevistas y grupos focales (para este artículo, tradujimos al castellano las contribuciones en portugués).

Tras finalizar el trabajo de campo, las entrevistas y el grupo focal fueron transcritos y codificados con el software MaxQDA. Para tal codificación construimos una matriz analítica compuesta por seis macrocategorías: 1) Construcciones de la frontera; 2) Trayectorias de las migrantes fronterizas; 3) Inserción de las migrantes fronterizas; 4) Configuraciones del cuidado fronterizo; 5) Experiencias de violencia; 6) Conexiones triple frontera Andina y del Paraná. Cada una de ellas se encontraban subdivididas en un total de 130 códigos. Los temas tratados aquí fueron clasificados como vinculados a la macrocategoría "Construcciones de la Frontera", bajo los códigos: i) Estrategias políticas de vinculación transfronteriza; ii) Estrategias identitarias de vinculación transfronteriza; iii) Discursos de alteridad y diferencia; iv) Discursos de odio; v) Prácticas de alterización/diferenciación; vi) Nacionalismo; vii) Xenofobia; viii) Racismo.

Las descripciones etnográficas desarrolladas por la autora y el autor, junto con los relatos que derivan de las entrevistas realizadas y del grupo focal, constituyen los recursos empíricos con los cuales rastreamos los impactos de los discursos antimigratorios en Foz.

\section{Bolsonaro: el discurso antiinmigrante}

El 9 de enero de 2019, una semana después de hacerse cargo de la presidencia, a través de su cuenta en Twitter, Bolsonaro anunció que retiraba a Brasil del Pacto Mundial para la Migración Segura, Ordenada y Regular, de la Organización de las Naciones Unidas (onU). ${ }^{4}$ Así Brasil y Chile (único país latinoamericano que no firmara el pacto) se unían a los Estados-nación más reactivos en torno al tema migratorio: Estados Unidos (EEUu), Hungría, Israel, Polonia y República Checa. A diferencia de estos países, Brasil detenta más emigrantes (tres millones) que inmigrantes (800 000) (Armendáriz, 2019). Pero no era difícil suponer que esta sería la postura de Bolsonaro. Antes de asumir, en diciembre de 2018, justificó dicha decisión al emitir su juicio a través de una descripción, a nuestro juicio xenófoba, de lo que, según él, ocurre en Francia:

Está siendo insoportable vivir en algunos lugares de Francia y la tendencia es un aumento de la intolerancia. Los que fueron hacía allí, el pueblo (francés) los acogió de la mejor manera posible, pero ustedes saben de la historia de esas personas, ellos tienen algo dentro de sí que no abandonan sus raíces y quieren hacer prevalecer su cultura, sus derechos de antes, sus privilegios $(E l$ Periódico, 2018).

En la comparación de Brasil con países con altos niveles de migrantes, el mandatario explicitó que extranjeros y nacionales no deberían tener los mismos derechos, y debían

\footnotetext{
${ }^{4}$ Un tratado no vinculante que recomiendo mecanismos para buscar soluciones integrales a las migraciones internacionales. En él se proponen 23 objetivos para desalentar la migración indocumentada, formas para proteger a los migrantes, su integración o para facilitar la migración de retorno.
} 
privarse los primeros de sus prácticas culturales. La declaración atenta en contra de los artículos 22 y 27 de la Declaración Universal de los Derechos Humanos (DUDH) que establecen, respectivamente, que todas las personas deben tener salvaguardadas "la satisfacción de los derechos culturales, indispensables a su dignidad y al libre desarrollo de su personalidad" y el "derecho a tomar parte libremente en la vida cultural de su comunidad" (onU, 1948).

Pese a que el pacto propuesto por la onu no implica asumir cualquier exigencia concreta, Bolsonaro se justificó argumentando que "Brasil es soberano para decidir si acepta o no migrantes”. Así, tensionaba la opinión pública brasileña, al establecer sin cualquier evidencia fáctica- que mantenerse en el acuerdo significaba mermar la soberanía nacional. Además, yuxtapuso la figura de los migrantes a la pérdida de la soberanía, igualándolos a una "amenaza" a la población autóctona. En la misma línea que Trump y Sebastián Piñera (presidente chileno), habló de la "necesidad" de aplicar políticas de seguridad fronteriza contra los migrantes, y comparó el país con su propia residencia: "no cualquiera entra en nuestra casa, ni cualquiera entrará a Brasil vía pacto adoptado por terceros" (France24, 2019). El canciller brasileño, Ernesto Araújo, agregó: "Brasil no puede dejar las puertas totalmente abiertas para que quien quiera entre" (El País, 2019). Así, el país es representado como el hogar de los gobernantes — todos hombres y blancos-, quienes deciden abrir o cerrar sus puertas. Se retrata, entonces, como una propiedad masculina cuyo control debe ser ejercido por sobre los marcos jurídicos establecidos a partir de la voluntad de control del hombre que gobierna.

Simultáneamente, al retirarse del pacto de la onU, Bolsonaro dejó desprotegidos a sus emigrantes, lo que provocó revuelta y desconcierto entre sus electores. Este es el caso de la comunidad brasilera de más de un millón de personas en EEuU. La decisión choqueó a la colonia que votó mayoritariamente al mandatario (que obtuvo $81 \%$ de votos de los brasileños residentes en Eeuu en la segunda vuelta de las elecciones presidenciales de 2018) (Brotto, 2019).

Bolsonaro reproduce, además, otros términos de la retórica de Trump, y establece una asociación directa entre narcotráfico, seguridad y migración. Esta vinculación carece de respaldo empírico, tanto en las estadísticas oficiales brasileñas y estadounidenses, como en la investigación social sobre estos fenómenos. Empero, Bolsonaro la reitera respaldándose frecuentemente en informaciones falsas (Cunha et al., 2019). Con la misma "ligereza", compara el contexto migratorio brasileño (con $0.4 \%$ de población migrante) con el de EEUU ( $14 \%$ de migrantes) (International Organization for Migration [IOM], 2018, p. 69).

En marzo de 2019, Bolsonaro tuvo un encuentro con Trump en Washington, donde manifestó su apoyo al plan de construir/agrandar el muro entre México y EEuU. Tras el encuentro, en entrevista a la cadena estadounidense Fox News, aseveró que "la mayoría de los potenciales inmigrantes no tiene buenas intenciones" (Huffington Post, 2019). Algunas horas después, tras recibir contundentes críticas, enunció lo contrario: "la mayoría de los migrantes tienen buenas intenciones" (Soares, 2019).

En tal ocasión, el hijo del presidente, Eduardo Bolsonaro (diputado del congreso nacional brasileño), expresó que "los migrantes brasileños en situación ilegal eran una vergüenza nuestra” ( $L a$ Voz, 2019). En reacción, mujeres de la comunidad brasileña del estado de Massachusetts (EEUU) manifestaron: "Estamos acostumbrados a defender nuestra comunidad de la persecución, discriminación y xenofobia del gobierno norteamericano. Nosotros nunca pensamos que precisaríamos defender a los brasileños del gobierno brasileño" (Brotto, 2019). 
Desde 2018, Bolsonaro viene usando el impacto generado por la migración de venezolanos a Brasil como estrategia mediática. El contingente venezolano emigrado a Brasil reúne cifras menos expresivas que la de países vecinos, pero el asunto fue tratado por Bolsonaro y sus ministros como una "invasión". El ingreso de cerca de 130000 por vía terrestre al norteño estado brasileño de Roraima ocupó un lugar importante en los medios de comunicación, lo que fue capitalizado por el gobierno como argumento central en su discurso anti-izquierda (Armendáriz, 2019). En agosto de 2019, tras las elecciones Primarias Abiertas Simultáneas y Obligatorias (PASO) en Argentina, Bolsonaro nuevamente esgrimió una frase que yuxtapone a los gobiernos de izquierda con los movimientos migratorios:

Si estos izquierdosos vuelven a la Argentina podremos tener en Río Grande do Sul un nuevo estado de Roraima. No queremos eso, no queremos hermanos argentinos huyendo hacia acá, teniendo en vista que algo malo puede ocurrir si se repite en octubre el resultado de ayer (Télam, 2018).

Argentina, país que protagonizó varias crisis económicas y políticas durante su historia, nunca tuvo a Brasil como un destino migratorio prioritario. Así, la retórica de Bolsonaro busca establecer una comparación entre Argentina y Venezuela vinculando el rechazo a gobiernos de izquierda con la intolerancia hacia los migrantes. Pese a no estar respaldados por datos institucionales o de investigación, estas declaraciones mueven sentimientos profundos entre los brasileños que atraviesan una fuerte crisis de confianza en las instituciones y de confrontamiento de las informaciones producidas por medios de comunicación. Así, la retórica de Bolsonaro estimula una semántica del miedo con impactos importantes en las cosmovisiones de diversos sectores de la población brasileña. Alimentan el ataque a cualquier grupo identificado como "minoría”. Veremos cómo estas elaboraciones se contextualizan en Foz.

\section{El contexto}

La triple frontera del Paraná es una de las zonas fronterizas más famosas de Latinoamérica (Agulló, 2017, p. 59). Ostenta el mayor flujo humano, de mercancías (Rhi-Sausi \& Oddone, 2010), de turismo (Cury \& Fraga, 2013) y de actividades ilícitas de toda Sudamérica (Cardin, 2012, p. 208). ${ }^{5}$ Su ámbito territorial está formado por la conurbación de tres ciudades (Albuquerque, 2012) con más de 600.000 personas (Renoldi, 2014, p. 2).

Puerto Iguazú, del lado argentino, es la más chica de las tres —42.849 personas en el censo argentino de 2010 (Dachary \& Arnaiz, 2012). Fundada en 1902, integra el Departamento de Misiones (Renoldi, 2013). Su principal actividad es el turismo (dirigido a las Cataratas del Iguazú) y está vinculada al lado brasileño a través del Puente de la Fraternidad (Giménez, 2011, p. 8), inaugurado en 1985. Ciudad del Este, del lado paraguayo, fue fundada en 1957 por un decreto presidencial (Lynn, 2008) y con la finalidad de servir de enganche territorial con Brasil. Bajo la dictadura de Stroessner (1954-1989) fue denominada "Puerto Flor de Lis" y, luego, "Puerto Presidente Stroessner”, en honor al dictador. En 1989, después de un plebiscito, recibió su actual

\footnotetext{
${ }^{5}$ Especialmente el tráfico de drogas y mercancías, el crimen organizado (Cardin, 2012) y la trata de mujeres y menores (Organización Internacional del Trabajo [OIT], 2002; Zsögön, 2013).
} 
designación. En la década de 1980 fue elevada a Zona Franca, transformándose en un gran centro de comercio internacional (Cardin, 2012). En el último Censo Paraguayo (del 2012), contaba con 312652 habitantes. Foz de Iguazú, del lado brasileño, es la más antigua de las tres. Se fundó en el siglo xix como un asentamiento militar (Catta, 2009; Renoldi, 2013), pero su crecimiento empezó en 1965 cuando, en concordancia con los proyectos desarrollistas realizados en la región, se construyó el Puente de la Amistad que la conecta con el lado paraguayo (Lynn, 2008). En el último censo brasileño (del 2010), contaba con 256081 habitantes (Albuquerque, 2012, p. 191).

Estas tres ciudades se interpelan fuertemente en términos económicos, políticos y culturales: es muy difícil comprenderlas por separado (Albuquerque, 2012). Como argumentaron Albuquerque (2012), Cardin (2012) y Renoldi (2013), el peculiar dinamismo de esta triple frontera se caracteriza por unos circuitos de movilidad y de relaciones (económicas, sociales y culturales) en las que legalidad e ilegalidad, pertenencia y desarraigo no son pares antagónicos (Lima \& Cardin, 2019, p. 10). Así, la vida cotidiana de quienes habitan en este territorio conlleva el constante cruce entre fronteras, entre ciudades. ${ }^{6}$

Pero para entender esta configuración territorial debemos retroceder en el tiempo. La revisión histórica revela que el militarismo cumplió un papel fundamental para las tres ciudades: sus adscripciones a las soberanías de Argentina, Brasil y Paraguay devienen de procesos bélicos que siguen influenciando la organización social y política del territorio. Desde el término de la guerra del Paraguay (1864-1870), ${ }^{7}$ esta área estuvo semipoblada y solo se transformó en una zona estratégica para el Cono Sur Americano entre 1960 y 1980 (Albuquerque, 2012), cuando se pactaron los planes de construcción de las hidroeléctricas de Itaipú (1971-1985), entre Brasil y Paraguay, y de Yaciretá (1983-2011), entre Argentina y Paraguay (Renoldi, 2013, p. 125). Ambas fueron proyectadas por gobiernos militares de los tres países, a partir de proyectos desarrollistas con impactos sociales sustantivos (Lins Ribeiro, 1999), ${ }^{8}$ para los cuales los gobiernos no se prepararon suficientemente (Renoldi, 2013). La dinamización impulsada por las hidroeléctricas provocó un sostenido crecimiento demográfico en la triple frontera (Lynn, 2008), pese a que el lado argentino permaneciera menos poblado por una decisión de los militares en la dictadura de Videla (1976-1981). ${ }^{9}$ No obstante al crecimiento de la zona entre 1970 y 1980, es solo con la firma del Mercado Común del Sur (Mercosur), en 1991, que ella fue efectivamente entendida como un área trifronteriza (Giménez, 2011; Rabossi, 2004).

\footnotetext{
${ }^{6}$ Esta movilidad es más distendida entre el lado brasileño y el paraguayo: los habitantes refieren al límite entre ellos como una "frontera abierta", dada la laxitud fiscalizadora de las autoridades. Esto no implica que los cruces entre Brasil y Argentina y entre esta última y Paraguay no sean intensos. Son, esto sí, mucho más controlados por las autoridades argentinas, mereciendo la denominación de "frontera cerrada" de los habitantes trifronterizos.

${ }^{7}$ El conflicto enfrentó la Triple Alianza (Brasil, Argentina y Uruguay, con apoyo británico) al ejército paraguayo motivado por contiendas respecto a intereses económicos y de determinación de los territorios, soberanías y fronteras (Reber, 1988). La victoria de la Alianza alimentó de simbolismos militares y raciales la noción de las diferencias étnico-identitarias entre Brasil y Argentina en contraposición a Paraguay. Brasileños y argentinos, cada uno a su modo, proyectaron su victoria como prueba de una supuesta superioridad racial, moral y civilizatoria. Estos imaginarios siguen vigentes tanto en Brasil (Souchaud, 2011) como en Argentina (Grimson, 2012).

${ }^{8}$ Por ejemplo, dotaron el área de una infraestructura de transporte fluvial y terrestre de las más articuladas del Cono Sur (Lynn, 2008).

${ }^{9}$ Cuando Argentina optó por reducir la presencia del Estado en las ciudades fronterizas con Brasil.
} 
Pero volvamos por unos instantes al periodo dictatorial. Foz representó, para la dictadura militar brasileña (1964-1986), un territorio prioritario de despliegue del proyecto nacionalista de control territorial y de hegemonía militar sobre los Estados vecinos (Ribeiro, 2006, p. 53; Sessi, 2015, p. 25). La construcción de las grandes obras militares y, entre ellas, la hidroeléctrica de Itaipú, enmarcó la formación de sendos complejos públicos brasileños en la triple frontera (Heller, 1988): redes de carreteras, aeropuertos y servicios públicos (escuelas, universidades y el principal hospital público de la región). Estas constataciones aparecen en los relatos de nuestros entrevistados como ЕмтP, brasileño, funcionario público estatal brasileño en Foz:

Foz fue una ciudad que, hasta la década de 1950, 1960, era totalmente desvalorizada. Era pequeñísima; era una colonia hasta 1900. Aquí prevalecían argentinos y paraguayos. El brasileño siempre fue minoría. Entonces vino Itaipú [la hidroeléctrica]. Entonces las cosas empezaron a cambiar; la geopolítica brasileña unifica e intenta influenciar Paraguay: una geopolítica de frontera que construye Itaipú (ЕмTP, brasileño, 20/07/2019).

Todo este complejo de obras y servicios popularizaron entre los habitantes locales la hegemonía estatal brasileña. Esto no implica que estas obras estuviesen libres de la violencia y represión militarista, elementos que estructuraron muchas de las vidas de los trabajadores empleados en la hidroeléctrica (Sessi, 2015). Pero el imaginario social de Foz sigue contando esta historia desde la perspectiva de las élites beneficiadas con el ciclo militar (Ribeiro, 2006, p. xvi; Sessi, 2015, p. 18). Esto nos lo explicaba DMMF, brasileño, profesional contratado en la Unila: "porque Foz realmente tiene esta cosa, esta onda militar. Esto es difícil de romper, hay varias barreras allí para ser deconstruidas" (DMMF, brasileño, 20/07/2019).

Mientras la hidroeléctrica estaba en construcción (1975-1986) se demandó mano de obra masculina en larga escala (Ribeiro, 2006; Sessi, 2015). Según I. (56 años, taxista, extrabajador de la construcción de Itaipú), a quien entrevistamos en Foz (el 29/07/2019), las labores de construcción funcionaban 24 horas diarias, en tres turnos, empleando 40000 trabajadores. Foz tenía una población total de 20000 personas cuando las obras se iniciaron (Sessi, 2015). Los sueldos en Itaipú eran bastante elevados comparados con el mercado laboral de otras ciudades brasileñas: esto atrajo una ingente migración interna, desplazada de diversas regiones brasileñas. ${ }^{10}$ En la construcción, los trabajadores contaban con una cobertura de seguros de riesgos, ayuda para alimentación, apoyos para estudios de los hijos, vacaciones cubiertas, atención sanitaria. Para dotar a la ciudad de infraestructura para los funcionarios de la empresa, toda Foz fue reurbanizada, ganando avenidas, jardines, parques. Sobre esto, subrayamos dos aspectos:

Primero: la estrategia de despliegue estatal de la dictadura brasileña implicó una diferencia sustantiva con los modelos militares argentinos y paraguayos de la época. En Brasil no se institucionalizaron las reformas neoliberales de reducción del Estado: desde 1968, la dictadura adoptó una perspectiva estatizadora de la economía, promoviendo una industrialización primaria para consumo internacional, invirtiendo en la infraestructura portuaria, de transportes e industrial general (Bellingieri, 2005). Todos estos aspectos integraban un plan de control social y territorial. Foz constituyó

\footnotetext{
${ }^{10}$ Además de I., que migrara desde Minas Gerais para trabajar en Itaipú, entrevistamos también a S., que migrara desde el nordeste brasileño, y P., que migrara desde el estado de Goiás, en el centro-oeste del país.
} 
uno de los principales enclaves condensadores de esta política militar-estatista que solo dejó de constituir un vector nacional en la década de 1990, con las reformas neoliberales realizadas en democracia (Sader, 1999; Sallum, 1999).

Segundo: esto alimentó, en el imaginario de los habitantes de la ciudad, una asociación directa entre el régimen militar y una era en que Foz vivía una bonanza (económica, laboral y de servicios) que se agotó con la conclusión de la obra de construcción de la hidroeléctrica, en 1986, año que inicia la transición democrática brasileña. La democracia marca, entonces, un momento en que el mercado laboral de Foz se ve afectado por el desempleo de alrededor de 40000 trabajadores, de los cuales algunos iniciaron el contrabando a pequeña escala con la Zona Franca de Ciudad del Este (entonces en ciernes). El desempleo masivo en Foz ocurriría con o sin los militares - la obra se terminaría en algún momento-, pero el imaginario popular yuxtapuso democracia a desempleo y militarismo a bonanza. Los ciclos económicos que se siguieron en la ciudad jamás pudieron cobijar un mercado laboral tan extenso para trabajadores no cualificados como el que caracterizó la construcción de la hidroeléctrica. Entre 1986 y 2008, Foz se convirtió en un centro nacional de peregrinaje de personas que pernoctaban del lado brasileño para comprar en Paraguay y, luego, con el contrabando hormiga, llevar estos productos a diversas regiones brasileñas. En este periodo, la ciudad entró definitivamente al circuito internacional del narcotráfico, economía que reestructuró violentamente todo el entorno local. A partir de 2004, con la caída del poder adquisitivo de la moneda brasileña y la valorización de dólar en el mercado internacional, el comercio con Ciudad del Este entró en colapso y Foz se reorientó al turismo. Esta actividad está fuertemente financiada por los capitales del contrabando y del narcotráfico, según indicó TVTw, abogada experta en crímenes de lavado de dinero, que actúa entre Foz y Ciudad del Este (TVTw, brasileña, 01/08/2019).

El PT, que comandó el gobierno federal brasileño durante los mandatos presidenciales de Lula da Silva (2002-2005; 2006-2011) y Dilma Rousseff (2011-2014; 2014-2015), tenía una visión clara sobre la centralidad de Foz para el proyecto político nacional (Rhi-Sausi \& Oddone, 2010). Pensaban la ciudad y la triple frontera como ejes aglutinadores de los intercambios regionales sudamericanos, que constituían la principal agenda política de inserción internacional de la economía brasileña en aquellos años. Pensaban convertir la ciudad en un epicentro del Mercosur (Alarcón, 2019, p. 33).

Con esto en mente, Lula presentó al congreso nacional (en diciembre de 2007) la Ley 12.189, que propone la creación de la Universidad de la Integración Latinoamericana (Unila) en Foz (Alarcón, 2019, p. 32). El proyecto fue aprobado por las comisiones del Congreso Nacional y del Senado y fue sancionado por el presidente Lula en enero de 2010 (Alarcón, 2019, p. 32). Su primer grupo de 200 estudiantes inició sus clases en agosto de este año. La propuesta dispone que la universidad ocuparía los predios del Parque Industrial de Itaipú que, considerado "zona estratégica nacional", ${ }^{11}$ se mantuvo bajo el control estricto del ejército brasileño, incluso tras la redemocratización. Hay en Foz diversas áreas no construidas que pudieran cobijar a un proyecto universitario de esta envergadura: sería ingenuo no suponer una intencionalidad política en este gesto del presidente, buscando resignificar uno de los símbolos del militarismo

${ }^{11}$ El espacio donde funciona la planta hidroeléctrica de Itaipú es considerado zona de alta seguridad nacional porque produce $80 \%$ de la fuerza eléctrica utilizada por los polos industriales brasileños. 
brasileño y convirtiéndolo en el corazón de la vocación latinoamericanista de Brasil. La construcción de la Unila se refería a la puesta en marcha de un plan que buscaba reincorporar las vinculaciones con los países del entorno (Ricobom, 2010), instigando la integración intercultural y sentando la "vocación brasileña" por coordinar la "unión de los pueblos latinoamericanos". Los estatutos de fundación de la universidad declaran que ella:

Nace de la urgente necesidad de nuestros pueblos de promover, a través del papel estratégico de la educación y del conocimiento compartido, una cultura de paz, de respeto, de solidaridad y de cooperación, para la construcción de sociedades sostenible en el siglo xxI, fundadas en la identidad latinoamericana en su diversidad cultural y orientación para el desarrollo, con justicia social y sustentabilidad socioambiental. (Alarcón, 2019, p. 32).

$\mathrm{Al}$ profundizar en estos valores, los estatutos proclaman como objetivo fundacional "combatir todas las formas de intolerancia y discriminación decurrentes de las diferencias lingüísticas, sociales, culturales, nacionales, étnicas, religiosas, de género y de orientación sexual" (Unila, 2009, en Alarcón, 2019, p. 32). Así, la Unila fue creada como una institución bilingüe (portugués-castellano), con la propuesta de tener $50 \%$ de estudiantes y docentes internacionales, provenientes de países latinoamericanos. Estas nociones fueron pensadas desde una articulación del centro del poder nacional que indagó muy poco sobre cómo la comunidad local recibiría estos valores. La propuesta careció, además, del sentido práctico tan necesario cuando se quiere desarrollar un proyecto universitario de esta naturaleza, como nos informó una profesora de la institución:

La Unila es un proyecto que lo pensaron personas muy poco prácticas. Tan poco prácticas que metieron el campus dentro de una zona de seguridad militar llena de barreras. Llena de “¡no! ¡Por acá, no puedes pasar!”. Una universidad que se abre al universo, pero dentro de una zona de seguridad militar. [...] Entonces la Unila pronto empezó a tener serias crisis, porque el proyecto se encontró con la realidad. Y con la realidad había que negociar, pero sin dejar de lado una utopía: la de una universidad temática para la integración. [...] Pero la Unila fue puesta en un lugar, en una ciudad, donde se le estigmatiza; donde es incómodo decir que sos profesora de la Unila. Si le agregas lo de argentina, lo de mujer y lo de extranjera, piensan que sos un proyecto del PT, una nave nodriza del PT; que ejemplificas la idea de relaciones diplomáticas del Pт[...]. Entones, dejan la Unila enclavada en una ciudad que la odia por otras razones. [...] La integración nunca tuvo una buena alfabetización popular, la población nunca supo de integración ni en Argentina, ni en Uruguay, ni en Chile, ni en Colombia. La integración parece simplemente un negocio de aduanas, de algunas cadenas productivas. Pero a nivel popular, nadie entiende bien para qué sirve el Mercosur, en qué les facilita la vida (SLF, argentina, 01/08/2019).

La frase de SLF - "dejan la universidad en una ciudad que la odia" - nos conecta con el imaginario militarista de Foz y con los sucesos políticos que provocaron un cataclismo en Brasil. Desde 2013, el nuevo ciclo de desaceleración de la economía brasileña — con la revalorización del dólar en el mercado nacional—, volvió a empujar la economía mercantil y turística de Foz a la recesión. Este ciclo estaba dado por 
factores macroeconómicos internacionales que impactaron casi todos los países del Cono Sur (Svampa, 2013). Pero en Brasil la centroderecha, apoyada en los medios de comunicación hegemónicos nacionales propulsaron una campaña de desprestigio de la gestión del PT.

Esta campaña — que sirvió como justificación del golpe que retirara a Rousseff de su segundo mandato-, impulsó una fuerte asociación del PT a los maleficios nacionales, progresivamente tornando legítimo el empleo de discursos de odio —racistas, xenofóbicos, clasistas, misóginos, macartistas- como expresión del descontentamiento popular (Pessoa do Amaral \& Arias Neto, 2017, p. 59). Estas medidas y discursos terminaron por legitimar, en casi todo Brasil, la noción de que el país estaría atravesado por una grieta ideológica insalvable: dos narrativas construidas entre quienes apoyan la derecha y quienes apoyan la izquierda (Ribeiro, 2018, p. 87):

Estamos en medio de una crisis, que es una crisis de identidad en Brasil. Que no es solamente una crisis política. Brasil se partió. Brasil se dividió entre personas que se preocupan con otras personas y personas que no se preocupan con otras personas (DMMF, brasileño, 20/07/2019).

Estos discursos fueron articulando la expresión pública del ataque a las minorías, al punto de validar la emergencia de Bolsonaro, de la extrema derecha, como candidato a la presidencia:

El discurso de odio sobre las minorías, movimientos sociales y sindicatos, la persecución a profesores y a la libertad de cátedra, el ataque a concepciones progresistas, el rechazo al bien público y la exaltación exacerbada del mercado vienen siendo algunas de las manifestaciones de esta especie de "reflujo" reaccionario (Casimiro, 2018, p. 43).

En Foz, este proceso fue absorbido desde un imaginario local que seguía proyectando a la dictadura como "el mejor momento de la historia del país", como nos dijo J., uno de nuestros entrevistados (Diario de Campo, Foz, 13/10/2018). Así, la ciudad vio incrementarse un fuerte sentimiento de rechazo a cualquier idea identificable con el PT. Al aunar la retórica latinoamericanista con el incentivo a la migración regional, con la noción de patria grande en sus principios fundacionales, la Unila se convirtió en un chivo expiatorio:

Entonces tienes una criminalización bien dirigida, direccionada al lulismo. Y es ahí donde tienes el movimiento pro-Bolsonaro y todo esto. La educación superior pública ahora es un enemigo que tiene que ser destruido, como una última voz de resistencia en Brasil (EMTP, brasileño, 20/07/2019).

Según informaciones entregadas por Rodrigo de Medeiros da Silva (vicerrector de Relaciones Internacionales e Institucionales de la Unila), actualmente, la universidad tiene más de 5000 estudiantes entre los cuales muchos provienen de otras regiones brasileñas. Solo $25 \%$ de ellos no son brasileños (es decir, la meta de $50 \%$ de matrículas extranjeras no se alcanzó). Las nacionalidades de estos estudiantes extranjeros son diversas, pero predominan estudiantes colombianos, ecuatorianos, haitianos y chilenos. Asimismo, Medeiros da Silva nos informó también que la institución ofrece más de 29 cursos (entre grado y posgrado) y su cuerpo profesional está compuesto por 374 profesores (menos de $30 \%$ no es brasileño) y 532 técnicos administrativos. 


\section{La Unila}

En el grupo focal que realizamos en la Unila, el 20 de julio de 2019, los relatos y diálogos sostenidos por estudiantes migrantes internacionales y funcionarios de la institución la dotan de una doble dimensionalidad: como un espacio de excepción y como contradicción.

\section{Espacio de excepción}

La universidad sigue, actualmente, estructurada a partir de la noción de integración latinoamericana. Los estudiantes de diversos países rescataron esta propuesta educacional, valorando su dimensión crítica:

Entonces, por ese lado, la universidad está dotada de un gran cuerpo de docentes que nos enseñan nuestra historia de América Latina: cómo se formó, la situación que vivieron todos los latinoamericanos. Cosas que en mi país yo no conocía. Porque la educación está dirigida al pensamiento europeo y nos desconocemos a nosotros como pueblo latinoamericano (JAMP, colombiano, 20/07/2019).

Lo que Foz tiene excelente es la Unila. Porque es gracias a la Unila que ha llegado gente de toda Latinoamérica y el caribe a Foz. [...] Yo he viajado a otros lugares de Brasil y no lo he visto. Es muy difícil: las personas no saben ni siquiera que son de Latinoamérica. Aquí en Foz saben que son de Latinoamérica (AHC, venezolano-libanés, 20/07/2019).

En comparación con Paraguay es una formación totalmente distinta. Una formación... Es una mirada macro de la integración latinoamericana y caribeña. A pesar de que, dentro de eso, hay una diversidad que se va colocando en el límite: hay investigaciones, visiones y uno va absorbiendo a partir de eso (RMVG, paraguayo, 20/07/2019).

Veo que hay mucho conocimiento [en la Unila]: personas preparadas para abrazar proyectos personales y todas las visiones que tienen. $\mathrm{Y}$ tenemos muchos estudiantes locales y extranjeros. Es un lugar de tierra fértil para poder conseguir puertas abiertas a nuestros sueños, a nuestras posibilidades de lo que es el desarrollo y la adquisición de nuevos conocimientos. Es importante la adquisición de una visión más amplia de lo que es nuestra Latinoamérica. [...] Pero desde que estoy aquí estoy dándome cuenta: ya no me siento, digamos así, únicamente colombiano. Ya me identifico con todo el pasado de Latinoamérica [...]. Es un asunto que está enriqueciendo mi persona y toda la perspectiva que tengo de mí mismo y de la región (FJVD, colombiano, 20/07/2019).

Así, la universidad constituye un "espacio de excepción" — la "tierra fértil", como la denomina FJVD-, organizándose alrededor de una noción de integración socialintercultural inusual en Brasil. Esta apertura a la diversidad contempla, también, la heterogeneidad sexual: 
Cuando llegue aquí tuve una experiencia. Mi forma de pensar no era la misma. Cuando llegue de mi país, estaba todo así, como quien diría... Por ejemplo: venía aquí al Jardín Universitario y había lesbianas, gays, todo eso. En Perú eso no se ve [...]. Tú vas a Perú y, no sé, una que quiere ser libre no lo consigue (MLPH, peruana, 20/07/2019).

Esta libertad de expresión resulta particularmente difícil de dirigir por la población de Foz: un entorno donde el rechazo a los migrantes, a los extranjeros (el miedo a la heterogeneidad social) se asumió como imperativo político hegemónico:

Políticos idiotas siempre hubo. Siempre va a haber. Pero el problema serio de Brasil es cuando el pueblo se parte. Y es ahí donde aparece aún más prejuicios, racismo, xenofobia. Este separatismo no debiera existir [...]. Yo realmente siento que, a veces, la gente, después de todo este tiempo de la Unila, la gente de Foz parece no saber de la existencia de la Unila [risas] (DMMF, brasileño, 20/07/2019).

Aquí empezamos a entender el sentido de la frase de SLF, cuando explicitaba que la universidad está incrustada "en una ciudad que la odia por otras razones". La Unila dona a la ciudad este sentido de pertenencia latinoamericana que despierta temor en los imaginarios locales fronterizos: el temor es tanto que la ciudad, como dice DMMF, se niega a verla, a reconocer su existencia. Para algunos, además de estar vinculado al militarismo que alteró tan fuertemente la ciudad, este rechazo a la diversidad se refiere al miedo a la contaminación por la frontera. ЕMTP, brasileño que migró a Foz para trabajar en la Unila, aclara:

Yo mismo no conozco a nadie de Foz. Cinco años aquí y no tengo amigos de Foz. No es tan fácil. Ellos son más cerrados. Es una cultura del interior. Yo tengo dificultades de adaptarme a la ciudad. Es una ciudad conservadora, moralista, cristiana y cerrada. [...] Entonces, creo que es un sentimiento de defensa, en una región donde pasa de todo. Pasan mercancías, personas, drogas, armas. Pasan inclusos órganos. Pasan cosas buenas y malas aquí en la frontera. Entonces, creo que las personas de este territorio son muy cerradas (ЕMTP, brasileño, 20/07/2019).

Su análisis indica que la fuerte adhesión a valores conservadores de la campaña política de Bolsonaro en Foz se vincula a la sensación permanente, por la población brasileña, de la inestabilidad de la condición fronteriza. NCA corrobora estas asertivas:

Yo tenía una visión diferente de Foz. Porque Foz es una ciudad de frontera, tiene muchos inmigrantes, extranjeros. Yo pensé que la gente era abierta, que no habría racismo. Y la cuestión de la Unila: tenemos miedo de decir que somos unileros, porque para la gente de Foz, la Unila... Por causa de nuestro estilo... Es difícil hacer amigos brasileños (NCA, haitiana, 20/07/2019).

No sería, entonces, un conservadorismo dirigido solamente a lo extranjero. EMTP (que es brasileño) tampoco pudo socializarse con nadie que no viniera de otro país o ciudad. Este "miedo" a "los otros" fue catalizado por los medios de comunicación y políticos locales que, observando su potencial como elemento de manipulación pública, empezaron una campaña mediática para yuxtaponer la Unila a elementos que, en los imaginarios locales, representan el peligro: 
Entonces, empiezan a divulgar que esta es una universidad local, vinculada a un gobierno bolivariano, petista, izquierdista, marihuanero... Como si los estudiantes de las universidades privadas no fumaran marihuana. Como si solo en la Unila se fumara. En las universidades privadas [de Foz] no se fuma, no se hacen fiestas, no hay sexo, no hay nada. Solo aquí se hacen fiestas. La policía, la comunicación social, los diarios, los tabloides, cuando pasa algún problema, que hay algún unilero, ellos van allá y dan todo el destaque. Para debilitar la imagen de la universidad (EMTP, brasileño, 20/07/2019).

Los estudiantes migrantes internacionales concordaron con estas apreciaciones y dieron testimonio de lo sorprendente que fue llegar a Foz y darse cuenta, por un lado, de la creciente campaña de desprestigio de la universidad y, por otro, que una ciudad fronteriza estaba cerrada a la diversidad. Según diversos comentarios, la barrera lingüística de los brasileños a aprender el castellano o el guaraní —idiomas de los países colindantes- sería una evidencia de este miedo a "la contaminación":

Bueno, al comienzo, antes de venir a la Unila, dije: "es una triple frontera. Hay dos países hispanos". Foz es relativamente pequeña, comparada con Ciudad del Este. Puerto Iguazú, que es la ciudad argentina aledaña hablaba portuñol. Yo pensé que no iba a ser tan complicado el idioma. Mi sorpresa, cuando llegue acá, es que muchísima gente que hasta trabaja en Paraguay no sabía casi nada de español. [...] Fue realmente un choque cultural. ;Impresionante! Porque yo vengo del caribe. [...] Fue un choque cultural, porque Foz de Iguazú es una mezcla de culturas (AHC, venezolano-libanés, 20/07/2019).

La Unila sería, entonces, una excepción a esta “cerrazón” cultural. A contracorriente de esta barrera lingüística, la institución incentivaría el contacto con idiomas locales, como el guaraní, que, por lo general, es rechazado por la población brasileña de Foz:

La universidad bilingüe: español y portugués. Pero hay curso de guaraní también. Y varias personas están haciendo el curso y ya te saludan en guaraní. Personas de Ecuador, Colombia, Argentina. O sea, son esas integraciones que uno va construyendo, que, a la vez, hacen más rica la universidad en cuanto a la cultura, lengua, pensamiento (RMVG, paraguayo, 20/07/2019).

\section{Espacio de contradicción}

Cuando preguntamos sobre la difícil conciliación entre los ideales integradores latinoamericanistas de la universidad y su puesta en marcha en Foz, emergió la definición de esta situación como una "contradicción", como un conflicto entre identidades:

Pensábamos que íbamos a encontrar un lugar integrado y resulta que venimos a ser parte de un proceso de integración. La Unila, como toda entidad, [...] es un proceso que parte del desorden y del caos y de una no-identificación [...]. Nosotros conformamos el cuerpo estudiantil y somos los que vamos a darle forma a lo que es el proceso de integración [...]. Entonces este proceso de integración requiere algo de paciencia porque no va a ser una integración 
momentánea, no va a ser una explosión de integración (FJVD, colombiano, 20/07/2019).

También los profesores brasileños sentían esta definición como precisa: "Entonces, realmente es esto. La Unila es esta maravilla que ustedes están viendo. Pero es todo este conflicto, esta contradicción también. Que es interesante: yo la estoy viviendo también" (LMA, brasileña, 20/07/2019). Es decir, la universidad sostiene una contradicción entre su propuesta, la sensibilidad político-identitaria de Foz y los desenlaces políticos brasileños (particularmente desde 2018). Esta contradicción permea la vida cotidiana de los estudiantes internacionales de dos formas. Primero: a través del rechazo xenófobo vivido en los espacios públicos urbanos y en las redes sociales:

La contradicción de que la Unila está ajena dentro de este sistema conservador [de Foz y brasileño]. Cuando se hizo la campaña a Bolsonaro hay compañeros y compañeras que sufrían violencia. O sea, sufrían violencia. Hay bares, por ejemplo, del centro, que se caracterizan que compañeras y compañeros [unileros] van a esos lugares. [...] Donde se acostumbra que compañeros y compañeras iban, ahí se sentían atacados. Incluso, creo que dos o tres personas sufrieron agresión física. También salió en el Facebook de la ciudad el rechazo a los extranjeros de la Unila (RMVG, paraguayo, 20/07/2019).

Varios relataron, por ejemplo, que los propietarios de inmuebles residenciales no alquilan a los unileros debido a la mala imagen que se hace de ellos. La mayor parte de los estudiantes buscaron soluciones habitacionales precarias por al menos un periodo de sus estadías en la ciudad, hasta lograr acceder a un arriendo medianamente digno. Muchos explicaron que, incluso en los anuncios de diario, los propietarios explicitan abiertamente el rechazo. Segundo: estos rechazos reproducidos por los estudiantes brasileños permean la universidad. La mayor barrera de integración estaría, precisamente, con los brasileños:

Pero la convivencia con brasileños...Yo no tengo amigos brasileños. Dicen que estamos en una facultad de integración. Podría ser, pero yo no tengo amigos brasileños. Yo me quedo en mi rincón, ellos en el suyo. Cada cual en su rinconcito; cada cual cuida de su vida, en su rinconcito. Y es así (CD, haitiana, 20/07/2019).

La convivencia es un poco difícil. A mí me costó hacer amistades mayormente con los brasileños. Y aunque a veces, no sé... En mi carrera, por ejemplo, hay grupos y es muy difícil vincularte a estos grupos.

Bueno, en mi caso, mayormente, tengo nomás amigos hispanohablantes (MLPH, peruana, 20/07/2019).

Hay grupos que no se integran con otros. Yo sí tengo algunos amigos brasileros. En ese sentido, me acogen bien. Pero sí sé que otros grupos tienen más dificultades para integrarse con brasileros (FJVD, colombiano, 20/07/2019). 
Tengo una complicación siempre con brasileros. Siempre el lenguaje separa a hispanos de brasileros. Yo tengo muchos amigos brasileros y ya domino muy bien el portugués. Porque me junto con ellos, aprendí con ellos. Pero si no hubiera sido por eso, mi grupo de amigos más cercano hubiera sido solo hispano (AHC, venezolano-libanés, 20/07/2019).

En estos relatos observamos que su presencia como estudiantes de la Unila les expone a procesos de exclusión social "interseccionales". Con esta expresión nos referimos a que sus condiciones de nacionalidad, género y la forma cómo son etiquetados racialmente por la población brasileña se superponen en el imaginario local, legitimando su marginación. Esta ocurre, por ejemplo, en relación con el mercado laboral:

Entonces, en el primer año, yo intentaba trabajar de la manera que fuera posible. Pero eso es parte del propio racismo. Bueno, no racismo: se llama xenofobia. Porque apenas ven que eres extranjero y no hablas el idioma bien, y necesitas el dinero y abusan... Por ejemplo, te dicen: "ya te pago tanto y trabajas tanto". Y como no tenías más opción: "bueno, ¿qué se le va a hacer?". Entonces tu trabajabas (AHC, venezolano-libanés, 20/07/2019).

La percepción de la condición migratoria permite al contratante brasileño jugar con la necesidad del joven y contratarlo por más horas y menos sueldo. El discurso de rechazo al "otro extranjero" sumado a la configuración de un entorno que precariza su experiencia urbana terminan habilitando su explotación económica: "bueno, sacan provecho de los extranjeros [...]. A veces con malicia: ven que no hay salida y, ahí, se aprovechan” (MLPH, peruana, 20/07/2019). La informalidad de la economía fronteriza agudiza estas explotaciones a los migrantes:

Entonces, es parte de esta informalidad aquí también. Varias veces él [su marido, extranjero] se negó a trabajar por que implicaba riesgo vital. Y yo, también, como profesora de la Unila conozco varios estudiantes que tuvieron accidentes [laborales] y que quedaron desamparados (LKMA, brasileña, 20/07/2019).

Para la mayor parte de los estudiantes, estas formas de discriminación estarían condicionadas por el sesgo racista de la mentalidad local: "Brasil es bastante racista y Foz es bastante. La mayor parte de la población. ¿Cómo decir? Es una generalidad" (RMVG, paraguayo, 20/07/2019). Este racismo cruza las fronteras del campus y permea la vida universitaria, estableciéndose en las relaciones de los estudiantes con sus colegas y profesores: "Ahora sobre el racismo: sí vi. En mi caso, sí pasé por un... Este... Por una discriminación. A parte, los profesores, a veces sin querer, lo hacen" (MLPH, peruana, 20/07/2019). Este es, entonces, una de las facetas contradictorias que asume la universidad:

La Unila va produciendo un estigma. Pero, a la vez, va produciendo contradicciones. Porque dentro de la universidad también se reproduce la cuestión del racismo, la xenofobia. Hace poco, compañeras y compañeros, no sé qué grupo específicamente, hicieron una campaña de visibilidad de la negritud. Tomaron fotos [de personas negras] y las pegaron en el pasillo de la universidad. Y fueron rayados, fueron arrancadas. O sea, dentro de la universidad misma, existe un racismo latente que se reproduce. Otro caso, 
una experiencia, que vi [...]. Creo que hubo un congreso de haitianos y un cartel que se pegó en la entrada de la facultad. Y el cartel se quitó y se tiró a la basura (RMVG, paraguayo, 20/07/2019).

Entre los estudiantes, aquellos que relataron experiencias más radicales de racismo y xenofobia fueron las mujeres negras. NCA y CD hablaron claramente de su marginación de la convivencia universitaria:

La Unila es integración, pero no hay integración dentro de la Unila. No hay integración: solo existen las personas de varios países dentro de la Unila [...]. Cada uno tiene su grupo. Hay el grupo de haitianos, el grupo de venezolanos, un grupo de paraguayos, brasileños. No hay integración. Para hacer los trabajos, si no hay ningún haitiano en la clase, yo lo tengo que hacer sola. No lo sé. Quizás [integración] es una bella palabra, pero una que no existe en la Unila. [...]. Hay mucho racismo también y puedo decir, después de tantos años, que no sé si esto va a cambiar [...]. La Unila reúne; pero la Unila también dispersa (NCA, haitiana, 20/07/2019).

Esta marginación —el que nadie quisiera hacer grupos de trabajo con ellas, por ejemplo-, guarda estrecha relación con la no aceptación de su cuerpo:

A veces es molesto. Nos molestan. Hay expresiones que son groseras. Y, para mí, la cuestión de mi pelo, también. Cuando dejo mi pelo suelto, las personas se quedan así, asustadas. Parece que no hay personas así aquí $[. .$.$] . Y cuando voy caminando en la calle, a veces me siento muy$ extranjera, porque las personas me miran distinto. No sé si es la cuestión del pelo, del cuerpo. Que tenemos una fisionomía diferente. Las personas nos miran más $[\ldots]$. Yo me siento un poco incómoda con esto (NCA, haitiana, 20/07/2019).

Las dos estudiantes llegaron desde Haití a Belo Horizonte, capital del estado de Minas Gerais, en el sudeste brasileño. Allá se sentían mejor tratadas, más integradas y sufrían menos discriminaciones racistas:

Yo viví en Minas Gerais y, para mí, no existía racismo. Llegué aquí a Foz: “¿Tu eres brasileña? ¿De dónde eres? ¿Eres africana?”. Y yo dije: "no, soy de Bahía” [estado brasileño con mayoría afrodescendiente]. Y: "ah, eres de Bahía”, y yo dije: “¿Pero aquí en Brasil no hay gente negra?”. Y: "sí, pero pensé que era de fuera” (CD, haitiana, 20/07/2019).

Según las reflexiones de los propios colegas hombres, los malos tratos hacia las colegas extranjeras estarían enmarcados en la mentalidad machista y sexista de Foz:

La mujer paraguaya es tratada muy mal. Es tratada como lo peor. La mujer brasileña es tratada como un pedazo de carne. E, imagínate, una mujer negra acá en Foz también es tratada mal. O sea, es vista como un objeto sexual. El machismo acá en Foz y en Paraguay es intenso, es fuerte. [...]. Varias compañeras de la Unila han reportado acá, como esperando el bus, que un hombre ha aparecido, ha bajado el vidrio y les ha gritado miles de barbaridades. Sexuales, obviamente. Porque, digamos, es extranjera: le pasa más a las extranjeras y a la mujer negra. Porque las ven como a un objeto sexual (AHC, venezolano-libanés, 20/07/2019). 


\section{Cierre}

Los temas tratados permiten tejer diversas interpretaciones sobre las consecuencias concretas de los discursos de odio en Brasil.

Del tercer apartado, donde revisamos los discursos del actual presidente, nos interesa rescatar cuatro conclusiones. Primero, que la xenofobia fue convertida en discurso oficial, y se articuló a enunciados que preconizan la intolerancia hacia las minorías y sectores vulnerables. Segundo, que estos usos fueron yuxtapuestos a las "ideologías de seguridad", que caracterizaron las dictaduras militares del Cono Sur entre las décadas de 1960 y 1980, y asociaron a las minorías con una condición de peligrosidad. La población migrante figura en estos discursos, entonces, como un ente pernicioso a la identidad nacional. Tercero, lejos de ser anodinos, estos usos construyen imaginarios y simbolismos que tienen una función política estratégica para el gobierno: legitiman instrumentalmente las propuestas de reforma legal de corte conservador. Cuarto, estos discursos ilustran la centralidad de las visiones patrimonialistas, patriarcales y racistas del Estado-nacional sobre las políticas migratorias, dándonos muestra de cómo estas lecturas vienen participando de las agendas neofascistas.

Estos cuatro aspectos se vinculan a un proceso histórico internacional que, por lo mismo, no se reduce al contexto brasileño. Las migraciones internacionales han sido muy frecuentemente usadas, en las últimas dos décadas, para constituir una imagen de "enemigos externos" o de "invasión nacional" que congrega sentimientos nacionalistas de fácil manipulación política: desenlace que observamos adquirir características de hegemonía cultural desde 2016, a partir de las elecciones presidenciales de Estados Unidos y de la votación del Brexit en Inglaterra. En un texto de los más sensibles, publicado poco antes de su fallecimiento, Bauman (2016) afirmaba que todos estos acontecimientos deben ser leídos a través de una clave política específica: habría que situarlos en el marco de una profunda crisis de conformación de la economía neoliberal global (cada vez más incapaz de restaurarse tras sus quiebres cíclicos) y de la incapacidad de los regímenes democráticos de conciliar los principios estructurales del estado de derecho con la intensificación del modelo neoliberal de acumulación. Como dijo Mirolslav Hroch hace ya dos décadas, el rechazo nacionalista a "los otros diversos", es "un sustituto de factores de integración en una sociedad que se está desintegrando. Cuando la sociedad fracasa, la nación aparece como la garantía última" (Hobsbawm, 1998, p. 183). Es en este sentido que la xenofobia y el racismo se van redimensionando, ganando cada vez más espacio en los imaginarios sobre los migrantes y la migración internacional. También en esto tenía razón Bauman (2016): se repite incesantemente en los medios de comunicación internacionales que estamos viviendo una "crisis migratoria", cuando, en realidad, el simple hecho de denominarla así es parte del problema, puesto que engendra la producción de odio a las minorías como una válvula de escape que alivia la tensión reinante, pero a precio de reproducirla y materializarla en un enfrentamiento y rechazo específico hacia ciertos grupos sociales. La "crisis" es del modo de producción y de su relación cada vez más conflictiva con las formas de institucionalidad política que son mínimamente necesarias para la existencia de regímenes democráticos.

Cuando nos acercamos al contexto concreto de Foz, observamos que estos imaginarios políticos encuentran un terreno fértil en una ciudad que ha reproducido - en sus representaciones y memorias sociales- la asociación del militarismo a la 
estabilidad económica, a los servicios públicos, a las grandes obras de construcción y a la "protección de la contaminación fronteriza". Foz es un espacio fronterizo cuyo crecimiento vertiginoso en la década de 1970 contribuyó al desarrollo de un imaginario local del miedo a la diversidad.

Los relatos analizados permiten explorar que la fuerte adhesión a los valores conservadores de la campaña política de Bolsonaro en Foz se vincula a la sensación permanente, por la población brasileña local, de inestabilidad respecto a su condición fronteriza. La gravedad de las cosas que pasan por esta frontera - crímenes tan variados como el tráfico de drogas o de órganos humanos- exponen a "los locales" a una situación constante de miedo. El miedo sería, entonces, el combustible que alimenta la poca apertura a lo desconocido, representado aquí por los extranjeros, la frontera o Latinoamérica. Así, la "cerrazón" y el conservadurismo de la población local — su tendencia a adherirse a discursos securitistas que reintegren las ideas de protección de una comunidad homogénea frente a amenazas externas- derivarían de la exposición a peligros difíciles de conllevar en las diversas esferas de la vida social en su carácter cotidiano.

Pero, como también nos relataron nuestros entrevistados, no se trata de un conservadurismo dirigido solamente a lo extranjero, sino, incluso, a lo extralocal. Este "miedo" a "los otros" habría sido catalizado por los usos de los medios de comunicación y los políticos locales que, observando su potencial como elemento de manipulación pública, empezó una campaña mediática con la finalidad de yuxtaponer a la Unila a todos los elementos. La Unila sería, en este contexto, un espacio de excepción, donde vemos desarrollarse un proyecto de integración para la diversidad, y un espacio de contradicción que, a contracorriente de su propuesta, reproduce discursos y prácticas xenofóbicas, racistas y homofóbicas. Es decir, la universidad sostiene una contradicción entre su propuesta, la sensibilidad político-identitaria de Foz y los desenlaces políticos del actual escenario brasileño.

Ahora bien, todas estas contradicciones y violencias están magnificadas para las estudiantes mujeres, migrantes y negras (como nos ha quedado claro con los relatos de nuestras entrevistadas haitianas de la Unila). Por lo general, la inserción socioeconómica de las mujeres en el mundo posglobalización se sedimenta en el reordenamiento, a escalas globales, de los sistemas de explotación y las jerarquías de género (Mills, 2003). Las mujeres son atravesadas, en realidad, por la interseccionalidad de elementos de marginación social, lo que las hace vivir procesos de condensación de las desigualdades sociales. Ellas experimentan la superposición de factores excluyentes vinculados a su adscripción étnica, de clase, de edad (Crenshaw, 1991, p. 1244) y de pertenencia nacional (añadiríamos al argumento de Crenshaw), que serán mucho más incisivos en su marginación, debido a que compaginan dichas características con su condición de subordinación de género en contextos globalmente patriarcales, machistas y androcéntricos. Esta experiencia de la interseccionalidad de factores excluyentes, que es vivida por las mujeres migrantes (en la triple frontera del Paraná y en diversos contextos), define sus espacios, derechos y posibilidades de incorporación social. Pero lo hace conjugando dos experiencias fronterizas simultáneas: la de pertenecer al "género otro" y la de desafiar a las fronteras (raciales, identitarias) del Estado-nación. 


\section{Agradecimientos}

Agradecemos a la Comisión Nacional de Investigación Científica y Tecnológica de Chile (Conicyt) que financia este estudio a través del proyecto Fondecyt 1190056.

\section{Referencias}

Agulló, J. (2017). Una revisión geopolítica de la Triple-Frontera del Paraná. En W. Soto (Ed.). Repensar las Fronteras. La integración Regional y el territorio (pp. 59-70). CLACSO, IDESPO, Universidad Nacional de Costa Rica.

Alarcón Mejía, D. M. (2019). Os Unileiros e a Xenofobia [tesis de posgrado, Universidad Federal de Integración Latinoamericana]. Repositorio institucional.

Albuquerque, J. L. C. (2012). Limites e paradoxos da cidadania no território fronteiriço: O atendimento dos "brasiguaios" no sistema público de saúde em Foz do Iguaçu (Brasil). Geopolítica(s), 3(2), 185-205.

Aquino, F. (2019). Ódio, combustível patológico. Galáxia. Revista do Programa de Pós-Graduação em Comunicação e Semiótica, (40), 180-183.

Armendáriz, A. (2019, 9 de enero). Bolsonaro quiere que los migrantes respeten las costumbres brasileñas y sepan cantar el himno. La Nación. https://www.lanacion.com.ar/el-mundo/bolsonaro-quiere-migrantes-respeten-costumbres-brasilenas-sepan-nid2209320

Bauman, Z. (2016). Extraños llamando a la puerta. Paidós.

Bellingieri, J. C. (2005). A Economia no Período Militar (1964-1984): crescimento com endividamento. Revista Hispeci Ẽ Lema, 8, 12-17.

Brotto, V. (2019, 20 de marzo). Como brasileiros no exterior reagiram às falas de Bolsonaro sobre migração. Migramundo. https://migramundo.com/como-brasileiros-no-exterior-reagiram-as-falas-de-bolsonaro-sobre-migracao/

Canelo, B., Gavazzo, N. \& Nejamkis, L. (2018). Nuevas (viejas) políticas migratorias en la Argentina del cambio. Si Somos Americanos, 18(1), 150-182. http://dx.doi. org/10.4067/S0719-09482018000100150

Catta, L. E. (2009). A face da desordem. Pobreza e estratégias de sobrevivência em uma cidade de fronteira (Foz do Iguaçú, 1964-1992). Blücher Acadêmico.

Cardin, E. G. (2012). Trabalho e práticas de contrabando na fronteira do Brasil com o Paraguai. Revista Geopolíticas, 3(2), 207-234.

Casimiro, F. H. C. (2018). As classes dominantes e a nova direita no Brasil contemporâneo. En E. Solano (Ed.), O ódio como política: a reinvenção das direitas no Brasil (pp. 42-48). Boitempo.

Crenshaw, K. (1991). Mapping the margins: Intersectionality, identity politics, and violence against women of color. Stanford Law Review, 43(6), 1241-1299.

Cunha, R., Menezes, L. F. \& Bodenmüller, L. (2019). Nos EUA, Bolsonaro cita informações falsas sobre imigração e antiamericanismo. Aosfatos. https://aosfatos. org/noticias/nos-eua-bolsonaro-cita-informacoes-falsas-sobre-imigracao-e-antiamericanismo/ 
Cury, M. J. F. \& Fraga, N.C. (2013). Conurbação Transfronteiriça e o Turismo na Tríplice Fronteira: Foz Do Iguaçu (Br), Ciudad Del Este (Py) e Puerto Iguazú (Ar). Rosa dos Ventos, 5(3), 460-475.

Dachary, A. C., \& Arnaiz, S. M. (2012). Región fronteriza de Argentina y Brasil: asimetrías y potencialidades. Revista Desenvolvimento Regional em Debate, 2(1), 204-231.

El País. (2019, 9 de enero). Brasil se retira del Pacto Migratorio de la onv: "No cualquiera entra en nuestra casa". https://www.elpais.com.uy/mundo/bolsonaro-anuncio-retiro-brasil-pacto-migratorio-onu.html

El Periódico. (2018, 19 de diciembre). Bolsonaro dice que adoptará un "criterio riguroso" para aceptar a los inmigrantes. https:/ /www.elperiodico.com/es/internacional/20181219/bolsonaro-criterio-riguroso-aceptar-inmigrantes-7209813

France24. (2019, 9 de enero). Bolsonaro tras retiro del Pacto sobre Migración: "Brasil es soberano de decidir si recibe o no migrantes". https://www.france24.com/ es/20190109-brasil-bolsonaro-pacto-migracion-venezolanos

Giménez, V. (2011). La "triple frontera" y sus representaciones: Políticos y funcionarios piensan la frontera. Frontera Norte, 23(46), 7-34.

Grimson, A. (2012). Mitomanías argentinas. Cómo hablamos de nosotros mismos. Siglo Veintiuno Editores.

Guizardi, M. L. (2019). The Age of Migration Crisis. Revista Tempo, 25(3), 577-598. https://doi.org/10.1590/tem-1980-542x2019v250303

Heller, M. I. (1988). Resistencia democrática: a repressão no Paraná. Paz e Terra.

Hobsbawm, E. (1998). Naciones y Nacionalismos desde 1780. Crítica.

Huffington Post. (2019, 19 de marzo). Bolsonaro: "La mayoría de inmigrantes no tiene buenas intenciones". https://www.huffingtonpost.es/entry/bolsonaro-mayoria-inmigrantes-no-tiene-buenas-intenciones_es_5c91261ee4b071a25a878fa1

International Organization for Migration. (2018). World Migration Report 2018. Іом.

La Voz. (2019, 19 de marzo). Bolsonaro ratificó su apoyo al muro de Trump: "La mayoría de los inmigrantes no tiene buenas intenciones". https://www.lavoz.com.ar/mundo/ bolsonaro-ratifico-su-apoyo-al-muro-de-trump-mayoria-de-inmigrantes-no-tiene-buenas-intencione

Lima, S. E. \& Cardin, E. G. (2019, mayo). As representações de mulheres na faixa de fronteira entre Brasil e Paraguai. Revista Caribeña de Ciencias Sociales. https:// www.eumed.net/rev/caribe/2019/05/representacoes-mulheres.html

Lins Ribeiro, G. (1999). Capitalismo transnacional y política hidroenergética en la Argentina. La represa de Yacyretá. Universidad Nacional de Misiones.

Lynn, J. (2008). La Triple Frontera y la amenaza terrorista ¿̇realidad o mito? En F. Rivera Vélez (Ed.), Seguridad multidimensional en América Latina (pp. 57-80). FLAcso Ecuador.

Matossian, B., Abal, Y. \& Melella, C. E. (2019). Políticas migratorias regresivas y desigualdades socio-territoriales: análisis de desde una perspectiva interescalar. Revista Electrónica del Instituto de Investigaciones Jurídicas y Sociales Ambrosio Lucas Gioja, (22), 29-62.

Mills, M. B. (2003). Gender and Inequality in the Global Labor Force. Annual Review of Anthropology, (32), 41-62. https://doi.org/10.1146/annurev.anthro.32.061002.093107 
Naciones Unidas (ONu). (1948). La Declaración de los Derechos Humanos. https://www. un.org/es/universal-declaration-human-rights/

Organización Internacional del Trabajo (оIт). (2002). Políticas sociales y ofertas institucionales para la confrontación de la explotación sexual comercial de niñas, niños y adolescentes en la frontera Paraguay-Brasil (Ciudad del Este). Autor.

Pessoa do Amaral, M. E. \& Arias Neto, J. M. A. (2017). Perversão e política no impeachment de Dilma Rousseff. Chasqui: Revista Latinoamericana de Comunicación, (135), 55-70.

Rabossi, F. (2004). Nas ruas de Ciudad del Este: vidas e vendas num mercado de fronteira [Tesis de doctorado, Universidade Federal do Rio de Janeiro].

Reber, V. B. (1988). The Demographics of Paraguay: A Reinterpretation of the Great War, 1864-70. Hispanic American Historical Review, 68(2), 289-319. https://doi. org/10.1215/00182168-68.2.289

Renoldi, B. (2013). Fronteras que caminan: relaciones de movilidad en un límite trinacional. Revista Transporte y Territorio, (9), 123-140.

Renoldi, B. (2014, octubre). Conceptos que hacen el Estado: crimen organizado y prácticas policiales en la Triple-Frontera. Actas del Seminario de Estudios sobre Saberes de Estado y Elites Estatales. Buenos Aires.

Rhi-Sausi, J. L. R \& Oddone, N. (2010). Cooperación e integración transfronteriza en el Mercosur: el caso de la triple frontera entre Argentina, Brasil y Paraguay. En L. Maira (Ed.), La política internacional subnacional en América Latina (pp. 209258). Libros del Zorzal.

Ribeiro, M. F. B. (2006). Itaipu, a dança das águas: histórias e memórias de 1966 a 1984 [tesis doctoral, Universidade Estadual de Campinas]. Repositorio Unicamp.

Ribeiro, M. M. (2018). Antipetismo e conservadorismo no Facebook. En E. Solano (Ed.), O ódio como política: a reinvenção das direitas no Brasil (pp. 87-94). Boitempo.

Ricobom, G. (2010). Unila: a contribuição do ensino para a integração da América Latina. Ideação, 12(1), 67-78.

Sader, E. (1999). Brasil: una historia de pactos entre elites. En A. A. Boron, J. C. Gambina \& N. Minsburg (Comps.), Tiempos violentos. Neoliberalismo, globalización y desigualdad en América Latina (Colección CLACSO-EUdEBA). CLACSO.

Sallum, B. (1999). O Brasil sob Cardoso: neoliberalismo e desenvolvimentismo. Tempo Social, 11(2), 23-47. https://doi.org/10.1590/S0103-20701999000200003

Sessi, V. (2015). O povo do abismo: trabalhadores e o aparato repressivo durante a construção da Hidrelétrica de Itaipu (1974 1987) [tesis de maestria, Universidade Estadual do Oeste do Paraná]. Blibioteca Digital de Teses e Dissertações. http://tede. unioeste.br/handle/tede/1723

Soares, J. (2019, 19 de marzo). Bolsonaro volta atrás: "Maioria dos imigrantes tem boas intenções”. O Globo. https://oglobo.globo.com/mundo/bolsonaro-volta-atras-maioria-dos-imigrantes-tem-boas-intencoes-23534610

Souchaud, S. (2011). A visão do Paraguai no Brasil. Contexto Internacional, 33(1), 131153.

Svampa, M. (2013, marzo-abril). "Consenso de los commodities" y lenguajes de valoración en América Latina. Nueva Sociedad, (244), 30-46. 
Télam. (2018, 8 de diciembre). Bolsonaro advirtió sobre una migración de argentinos si Alberto Fernández es presidente. El mandatario apoya abiertamente la reelección de Mauricio Macri. https://www.telam.com.ar/notas/201908/383757-bolsonaro-advirtio-sobre-una-migracion-de-argentinos-si-alberto-fernandez-es-presidente.html

Zsögön, M. C. (2013). Explotación sexual comercial infantil en la triple frontera entre Argentina, Brasil y Paraguay. Ideação, 15(2), 110-128.

Menara Lube Guizardi

Brasileña/italiana. Es doctora en antropología social por la Universidad Autónoma de Madrid (UAM, España). Actualmente se desempeña como investigadora posdoctoral del Consejo Nacional de Investigaciones Científicas y Tecnológicas (Conicet, Argentina) en el Instituto de Altos Estudios Sociales de la Universidad Nacional de San Martín (IDAes-unsam, Buenos Aires, Argentina) y como investigadora asociada de la Universidad de Tarapacá (Arica, Chile). Sus líneas de investigación son sobre migraciones, género y fronteras. Su último libro es Des/ventura de la frontera. Una etnografía sobre mujeres peruanas entre Chile y Perú, publicado en 2019 por Ediciones UAH.

Pablo Mardones

Chileno/uruguayo. Es doctor en antropología por la Universidad de Buenos Aires (Argentina). Se graduó como director de fotografía (DF) en el Centro de Formación Profesional (CFP) del Sindicato de la Industria Cinematográfica Argentina (SICA). Actualmente es investigador del Instituto de Estudios Internacionales de la Universidad Arturo Prat (Inte-unap, Iquique, Chile) y director de la productora de documentales etnográficos Alpaca Producciones (Iquique, Chile). Sus líneas de investigación son sobre etnografía audiovisual, fiestas populares y migraciones fronterizas. Su última publicación es "Política amerindia en Buenos Aires. La marcha de contra-festejo del 12 de octubre como construcción cronotrópica”, en Estudos Ibero-Americanos, 45(2), 106-120. 